\title{
Formulation and Validation of Recombinant Antigens CFP10 and ESAT6 for Tuberculosis Diagnosis
}

\section{Ludmilla Dela Coletta Troiano Araujo \\ https://orcid.org/0000-0003-1885-6758}

Daniel Ernesto Rodriguez-Fernández ${ }^{2}$

https://orcid.org/0000-0002-2700-8606

Susan Grace Karp ${ }^{1}$

https://orcid.org/0000-0001-7497-1641

Ellen de Souza Marquez ${ }^{1,3}$

https://orcid.org/0000-0003-3470-2783

\author{
Manuel Hospinal-Santiani ${ }^{1}$ \\ https://orcid.org/0000-0002-4775-9415 \\ Raphael Aparecido Boschero' \\ https://orcid.org/0000-0002-9668-7526 \\ Eliezer Lucas Pires Ramos ${ }^{1}$ \\ https://orcid.org/0000-0002-9437-5545
}

\author{
Vanete Thomaz-Soccol ${ }^{1 *}$ \\ https://orcid.org/0000-0001-9301-541X
}

\section{Aline Cristina dos Santos ${ }^{4 *}$ \\ https://orcid.org/0000-0003-1295-7857}

${ }^{1}$ Federal University of Paraná (UFPR), Bioprocess Engineering and Biotechnology Department, Curitiba, Paraná, Brazil; ${ }^{2}$ Federal University of Rio de Janeiro (UFRJ), School of Pharmacy, Rio de Janeiro, Brazil; ${ }^{3}$ State University of Northern Paraná (UENP), Veterinary Clinical Pathology Laboratory, Bandeirantes, Paraná, Brazil; "4Paraná Institute of Technology, Quality Control Department, Curitiba, Paraná, Brazil.

Editor-in-Chief: Alexandre Rasi Aoki

Associate Editor: Alexandre Rasi Aoki

Received: 2021.03.07; Accepted: 2021.06.28.

*Correspondence: vanetesoccol@gmail.com; Tel.: +55-41-33613272 (V.T.S.).

\section{HIGHLIGHTS}

- Recombinant protein formulations for the accurate diagnosis of TB are presented.

- Formulations of ESAT6:CFP10 proteins present long shelf life at room temperature.

- Protein formulations are effective in diagnosing active TB, in vitro and in vivo.

Abstract: The rapid and accurate diagnosis of tuberculosis (TB), especially considering limited resources, is still a challenge. Development of new methodologies and tests are needed to overcome several disadvantages of the available standard tests. We evaluated the diagnostic potential of two antigens specific for Mycobacterium tuberculosis, the CFP10 and ESAT6 recombinant proteins, and developed stable formulations thereof. Sensitivity and specificity of the delayed-type hypersensitivity (DTH) skin testing and the induction of gamma interferon production (IFN- $\mathrm{Y}$ ) by lymphocytes, as a non-invasive test, were evaluated using the CFP10 and ESAT6 protein formulations. The recombinant proteins produced by our group presented a high DTH response and the ability to differentiate between tuberculosis infection, BCG vaccination, and the contact with non-tuberculous mycobacteria (NTM). The production of IFN- $\gamma$ by stimulation with individual and combined proteins was detected in a panel of 40 individuals and showed a specificity of $100 \%$ and a sensitivity of $90 \%$ when the two proteins were used together. Lyophilized formulations were stable under all conditions, while soluble formulations were stable under freezing at 
$20{ }^{\circ} \mathrm{C}$ and $-80{ }^{\circ} \mathrm{C}$. The proposed formulations containing the ESAT6 and CFP10 recombinant antigens constitute satisfactory tools for TB testing, suitable to be developed and implemented in a large-scale trial.

Keywords: antigens; delayed-type hypersensitivity; gamma interferon; Mycobacterium tuberculosis; skin test.

\section{INTRODUCTION}

Tuberculosis (TB) is one of the leading causes of morbidity and mortality worldwide, accounting for about 1.4 million deaths in 2019 and 10 million new cases annually [1]. Latent TB infection (LTBI) affects around 1.7 billion people, of which $5-15 \%$ will suffer from reactivation of TB during their lifetime $[1,2]$. Rapid and accurate diagnosis is crucial to reduce transmission and enhance primary treatment of infection, and the use of tools able to detect LTBI is of extreme importance for TB eradication [3].

The tuberculin skin test (TST), or Mantoux test, is based on the intradermal injection of the purified protein derivative (PPD) antigens causing a delayed-type hypersensitivity (DTH) reaction that allows to detect both active and latent TB infection. Despite TST being the most used method for detecting tuberculosis infection, it has some disadvantages and limitations such as, cross reaction with non-tuberculous mycobacteria (NTM) species and reduced specificity in individuals who have previously received the Bacillus Calmette Guérin (BCG) vaccine. The presence of more than $200 \mathrm{M}$. tuberculosis antigens in the PPD contributes to its low specificity [4]. In order to overcome the low specificity issue, several recombinant protein antigens have been developed for use in TB diagnosis [5,6].

The interferon gamma (IFN- $\gamma$ ) release assay (IGRA) is an in vitro blood test based on cell-mediated immunity for LTBI diagnosis. IGRAs measure the amount of IFN-y produced in response to two recombinant proteins, ESAT6 (6-kDa-early secretory antigenic target) and CFP10 (10 kDa-culture filtrate protein), that are encoded by $M$. tuberculosis-specific region of differentiation 1 (RD1) [7]. These antigens induce a strong Tcell IFN-y response by the activation of Th1 cells [8], and do not elicit cross reaction with NTM or response in BCG-vaccinated individuals. In spite of the high specificity, this diagnostic method requires laboratory equipment and highly skilled technicians, hindering its implementation on a routine basis, especially in lowincome countries. The development of accessible high-quality tests able to detect both TB and LTBI with high specificity and sensibility is essential for the disease control and prevention $[9,10]$.

Formulation studies represent a critical step in the development of stable antigens. Protein degradation can occur in liquid and even in lyophilized forms. The selection of formulation components is dependent on experimental conditions, since their effect can vary depending on the protein sequence and structure [11]. Since TST is recommended by the World Health Organization (WHO) especially in developing and high TB burden countries [12,13], the present work evaluated two formulations containing CFP10 and ESAT6 recombinant proteins as skin test immunogens for diagnosis of $M$. tuberculosis infection, aiming to compensate the specificity disadvantages presented by the commercial PPD. In addition, the production of IFN-y was evaluated, as a non-invasive test, using the same two formulations produced by our group $[14,15]$.

\section{MATERIAL AND METHODS}

\section{Preparation and validation of the antigens}

The production and purification of the recombinant proteins CFP10 and ESAT6 was performed under optimized conditions, as previously described [14]. Briefly, the recombinant proteins were expressed in Escherichia coli and produced in batch submerged fermentation using a 10-L stirred tank bioreactor. Protein recovery was performed by ultrasonic disruption and solubilization of proteins from inclusion bodies under optimized conditions (biomass concentration of $15 \mathrm{~g}$ per $150 \mathrm{~mL}$ of sonication buffer, 12 disruption cycles and seven solubilization cycles). Purification was conducted by immobilized metal affinity chromatography (IMAC) and endotoxins were removed by the micellar method [16]. Analyses by sodium dodecyl sulfate polyacrylamide gel electrophoresis (SDS-PAGE), Western blot and identity confirmation by mass spectrometry were also described previously [14]. These proteins were evaluated as coating antigens in indirect Enzyme Linked Immunosorbent Assay (iELISA) and IGRA. 


\section{Preparation of antisera against Mycobacterium tuberculosis to determine the proteins specificity}

Polyclonal antibodies against $M$. tuberculosis were obtained by immunizing two New Zealand rabbits. Each animal received primarily $1 \mathrm{mg}$ of $M$. tuberculosis emulsified in Freund's complete adjuvant 1:1 (Sigma) by intramuscular route. Four booster injections were performed with $1 \mathrm{mg} \mathrm{mL}^{-1}$ of recombinant protein in equal volumes of incomplete Freund's adjuvant 1:1 (Sigma) at 10-days intervals to prolong the antigen exposure and stimulate the production of antibodies. Sixty days from the first stimulation, the animal blood was obtained from the rabbit's ear marginal vein and pooled to obtain a single sample. The rabbit pre-immune serum and the rabbit immunized serum (containing the polyclonal antibodies) were respectively considered as negative and positive controls to determine the recombinant proteins specificity.

\section{Development of iELISA with purified recombinant antigens}

To define the optimum working concentration for each of the coating antigens, a checkerboard titration was performed varying the protein concentration and dilution of primary (serum) and secondary antibodies. Briefly, 96-well microplates (Costar) were coated with $100 \mu \mathrm{L}$ per well containing 250,500 or $1,000 \mathrm{ng}$ of CFP10 or ESAT6 diluted in $0.1 \mathrm{M}$ carbonate coating buffer, $\mathrm{pH} 9.6$, overnight at $4{ }^{\circ} \mathrm{C}$. Following, the plates were washed three times with $0.1 \mathrm{M}$ phosphate buffered saline containing $0.3 \%(\mathrm{w} / \mathrm{v})$ Tween $20(\mathrm{PBST}), \mathrm{pH}$ 7.4 , and incubated with $100 \mu \mathrm{L}$ per well of a blocking solution composed of $3 \%(\mathrm{w} / \mathrm{v})$ bovine serum albumin (BSA) in $50 \mathrm{mM}$ Tris- $\mathrm{HCl}(\mathrm{pH} 7.4)$, for $1 \mathrm{~h}$ at $37^{\circ} \mathrm{C}$. Subsequently, $100 \mu \mathrm{L}$ of the positive and negative sera (including a blank of PBST as a negative control), in dilution ratios of 1:25, 1:50 and 1:100 (v/v), were added in duplicates and incubated for $1 \mathrm{~h}$ at $37^{\circ} \mathrm{C}$. After washing, anti-rabbit HRP secondary antibody (Sigma) was submitted to serial dilution ratio ranging from 1:2,500 to $1: 20,000(\mathrm{v} / \mathrm{v})$ and $100 \mu \mathrm{L}$ were added to each well. The washing steps were repeated three times. The reaction was revealed with $50 \mu \mathrm{L}$ of orthophenylenediamine (OPD) for $10 \mathrm{~min}$ at room temperature and stopped with $50 \mu \mathrm{L}$ of $2 \mathrm{M} \mathrm{H}_{2} \mathrm{SO}_{4}$ solution. Absorbance was measured at $450 \mathrm{~nm}$. The dilutions that showed the largest ratio between positive and negative sera $(\mathrm{P} / \mathrm{N})$ were selected as the optimal dilutions.

\section{Interferon-Gamma Release Assay}

The immunological reactivity to the standard PPD RT23 (Statens Serum Institut) and the M. tuberculosisspecific RD1 antigens was assessed by stimulating human peripheral blood mononuclear cells (PBMC). Twenty-seven patients with active tuberculosis were selected from São Sebastião da Lapa Hospital (Lapa, PR, Brazil). Individuals recruited for this study were aged 18 years old or older. Inclusion criteria were positive bacilloscopy for acid-fast bacillus resistant (AFB) test, mycobacteria culture and clinical diagnosis of mycobacterial infection. All patients had received treatment for TB. HIV positive test (ELISA) and/or immunodeficiency diseases were considered as exclusion criteria. The negative control group had thirteen healthy $M$. tuberculosis-unexposed individuals vaccinated against tuberculosis, negative for tuberculin skin test and/or negative for QuantiFERON-TB Gold (QFT) test.

The blood sample $(5 \mathrm{~mL})$ was collected from each participant. Subsequently, the monocytes were isolated from PBMCs using Ficoll-Paque density gradient. The pellet was suspended and washed twice with Roswell Park Memorial Institute (RPMI) medium. The cell solution $\left(1 \times 10^{6}\right.$ cells $\left.\mathrm{mL}^{-1}\right)$ was distributed, in triplicates, in 96-well plates for stimulus $\left(3 \mu \mathrm{g} \mathrm{mL}^{-1}\right.$ of ESAT6; $3 \mu \mathrm{g} \mathrm{mL} \mathrm{L}^{-1}$ of CFP10; $3 \mu \mathrm{g} \mathrm{mL}^{-1}$ of CFP10 and ESAT6; and $0.4 \mu \mathrm{g} \mathrm{mL}^{-1}$ of the standard PPD RT23) and in the absence of stimulus (negative control). Then, the plate was incubated in $5 \% \mathrm{CO}_{2}$ at $37^{\circ} \mathrm{C}$ for 5 days. The supernatants were pooled and frozen at $-20^{\circ} \mathrm{C}$ for further IFN- $\gamma$ quantification. The IFN- $y$ detection in culture supernatant was assayed using a Human IFNgamma DuoSet ELISA (R\&D Systems), according to the manufacturer's recommendations. The results were expressed in picograms per milliliter derived from the standard curve. The cut-off value was considered $>145$ pg IFN-y mL $\mathrm{mL}^{-1}$ discriminating responders from non-responder patients.

\section{Design of experiments for formulation development and validation in animal model}

\section{Formulation design}

The experiment was designed using recombinant proteins (CFP10, ESAT6, CFP10:ESAT6) in different concentrations $\left(0.4,0.04,0.004\right.$ and $\left.0.0004 \mathrm{mg} \mathrm{mL}^{-1}\right)$, eluted in two buffers labeled as: Formulation 1 (F1) (7.6 mg Na $2 \mathrm{HPO}_{4} . \mathrm{H}_{2} \mathrm{O}, 1.5 \mathrm{mg} \mathrm{KH}_{2} \mathrm{PO}_{4}, 4.8 \mathrm{mg} \mathrm{NaCl}, 100 \mu \mathrm{g}$ potassium hydroxyquinoline sulfate, $80 \mu \mathrm{g}$ Tween 20, and $\mathrm{H}_{2} \mathrm{O}$ q.s. ad $1 \mathrm{~mL}$ ); and Formulation 2 (F2) (phenolic saline $0.4 \%$ q.s. ad $1 \mathrm{~mL}$ ), and evaluated in two presentation forms, soluble and lyophilized. The components used in the formulations were selected 
according to the compatibility, administered dose and route of administration according to the regulatory guidelines.

Lyophilized formulations were prepared from F1 and F2 solutions. Prior to lyophilization, $5 \mathrm{~mL}$ of each sample were transferred to $20 \mathrm{~mL}$ glass vials and frozen at $-80^{\circ} \mathrm{C}$ for $16 \mathrm{~h}$. The vials were then loaded into the ModulyoD freeze dryer (Thermo Electron Corporation) and lyophilization was performed at $-45^{\circ} \mathrm{C}$ and 50 mbar for $24 \mathrm{~h}$.

\section{Delayed-type hypersensitivity responses in guinea pigs}

DTH reactions were evaluated in four groups composed of nine female white guinea pigs (Cavia porcellus) weighing approximately $300 \mathrm{~g}$, obtained from the Technology Institute of Paraná (TECPAR). Each group was sensitized by intramuscular injection in hind legs with $0.5 \mathrm{~mL}\left(2 \mathrm{mg} \mathrm{mL}^{-1}\right)$, per animal, of inactivated M. tuberculosis, M. bovis, M. avium and BCG vaccine (M. bovis BCG Moreau RDJ) [17]. Six weeks after the sensitization, the animals were shaved on the back and injected intradermally with $0.4,0.04,0.004$ and $0.0004 \mathrm{mg} \mathrm{mL}^{-1}$ of each purified antigen (CFP10; ESAT6 and CFP10:ESAT6) prepared as Formulations 1 (F1) and 2 (F2). Each animal was also injected on the right flank with 2 tuberculin units per $0.1 \mathrm{~mL}$ of PPD to control for sensitization and for the specificity of the assay. Two non-sensitized animals were used to evaluate the interference of the formulations F1 and F2 (without antigens) and of the host strain (E. coli) extract. The diameters of erythema were independently measured by two examiners who perform this test routinely, using the double-blind method $48 \mathrm{~h}$ after injection. An induration of $\geq 5 \mathrm{~mm}$ was considered as a positive response.

\section{Stability tests}

The stability assays were conducted under accelerated stress and real time conditions according to the guidelines of the National Regulatory Agency. This study aimed at assessing the sterility, integrity and functionality of the drug formulations under variations of temperature, humidity and light.

The stability tests were performed with the lyophilized and soluble formulations containing $400 \mu \mathrm{mL} \mathrm{m}^{-1}$ of recombinant protein. The samples were conditioned in a transparent neutral glass vial with a sealing cap and subjected to different temperature conditions: room temperature $\left(25^{\circ} \mathrm{C} \pm 2{ }^{\circ} \mathrm{C} / 60 \% \pm 5 \%\right.$ relative humidity, $\mathrm{RH})$, elevated temperature $\left(40^{\circ} \mathrm{C} \pm 2{ }^{\circ} \mathrm{C} / 75 \% \pm 5 \% \mathrm{RH}\right)$, cooling temperature $\left(2-8^{\circ} \mathrm{C}\right)$ and freezing temperatures $\left(-20^{\circ} \mathrm{C}\right.$ and $\left.-80^{\circ} \mathrm{C} \pm 2{ }^{\circ} \mathrm{C}\right)$. Samples were analyzed at different time intervals $(0,30,60,120$ and 180 days). The parameters and analytical methods used to verify the formulation integrity, purity, and potency were: appearance, aspect, and color (visually), $\mathrm{pH}$ by the potentiometric method (in the case of lyophilized samples, after resuspension to the initial volume) according to Sengupta and coauthors [18], protein concentration by a colorimetric method [19] and humoral and biological activity as described previously $[18,19]$. The sterility test was performed according to two official methods [20]: the direct inoculation method and the membrane filtration method. In both cases, the fluid thioglycollate medium (FTM) incubated at $30-35^{\circ} \mathrm{C}$, and the casein-soya medium incubated at $20-25^{\circ} \mathrm{C}$ were employed to detect fungal, yeast, aerobic and anaerobic bacteria. Samples remained in contact with the medium for 14 days (incubation period) to allow detection of slow growing microorganisms.

The photo stability testing of samples was conducted in (D65/ID65) light source according to the ICH Q1B guideline [21]. At the end of the exposed period, the physical properties of the samples were examined (appearance, clarity, or color). The formulations were also subjected to freezing and thawing cycles to evaluate protein destabilization and denaturation. Twenty-four-hour cycles were performed at alternating temperatures: room temperature and $-20 \pm 2{ }^{\circ} \mathrm{C}$, and this procedure was repeated three times. A shelf-life test was performed with the lyophilized formulations, which were stored at room temperature for nine months, and then evaluated visually and assayed for biological activity and protein concentration.

\section{Statistical analyses}

T-cell responses among groups were assayed for four different groups of patients inoculated with the proteins and one without inoculation as a negative control. Two-way Analysis of Variance (ANOVA) followed by Tukey multiple comparisons test was performed using GraphPad Prism version 8.0.0, GraphPad Software, San Diego, California USA. A p-value of $<0.05$ was considered statistically significant. 


\section{Ethics statements}

For animals, all procedures were carried out in strict compliance with the rules defined by the National Council for the Control of Animal Experiments (CONCEA), and every effort was made to minimize suffering. The work was approved by the Ethics Committee of the Federal University of Paraná, under protocol no. 469. All procedures performed in studies involving human participants were conducted in accordance with the International Ethical Guidelines for Biomedical Research and Resolution $n^{\circ} 196$ of the Brazilian Ministry of Health, National Health Council. In addition, ethical approval was obtained from the Ethical Committee CEP/SESA/HT number 196. All individuals received and signed the written free consent clause indicating that they agreed with the use of the samples.

\section{RESULTS}

\section{Preparation of the antigens}

The CFP10 and ESAT6 proteins were expressed and purified, and final yields achieved in bioreactor were 233 and $121 \mathrm{mg} \mathrm{L}^{-1}$ in the culture broth, respectively. Their identity was confirmed by mass spectrometry and the endotoxin level measured after the micellar treatment was lower than $0.5 \mathrm{EU} \mathrm{mL}^{-1}$.

\section{Validation of the antigens}

\section{Immunoreactivity by iELISA}

The optimal working concentrations of antigen, serum and conjugate in the iELISA were determined by checkerboard titration. The concentration of recombinant antigen yielding high specificity was obtained using $1000 \mathrm{ng}$ of CFP10 per well (Figure 1a) and $500 \mathrm{ng}$ of ESAT6 per well (Figure 1b). The optimal dilution ratios selected for primary (serum) and secondary antibodies were 1:50 and 1:5000 (v/v), respectively for both antigens. 
(a)
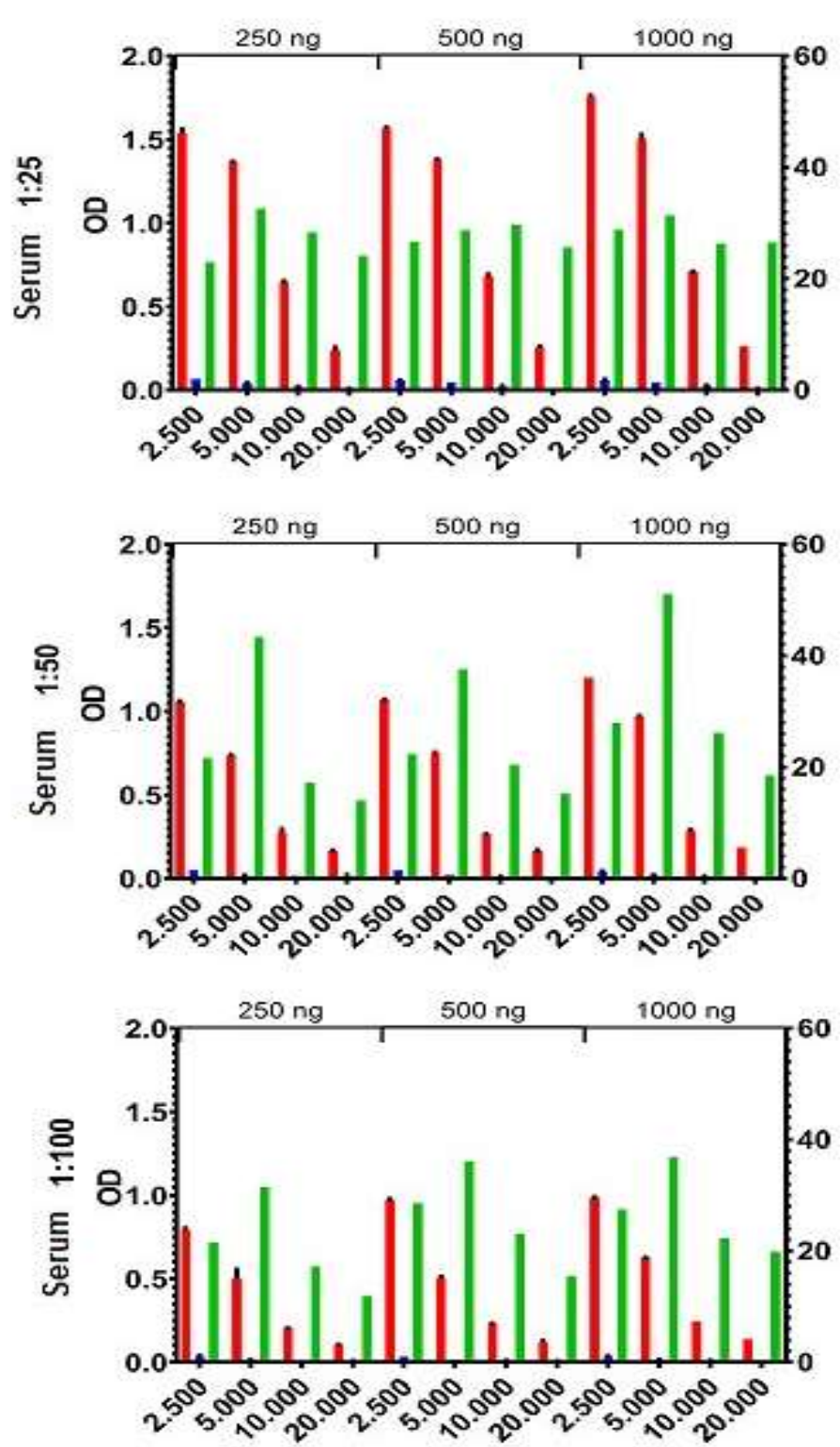

(b) ESAT 6
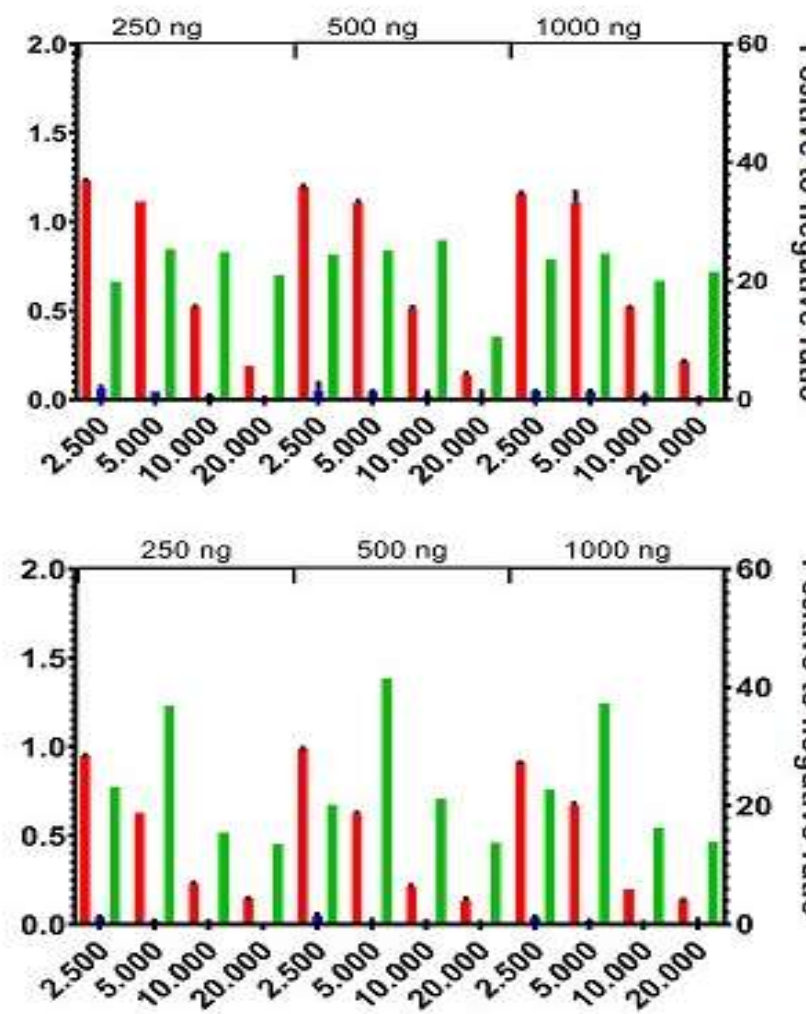

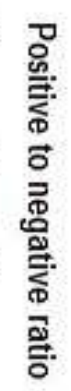

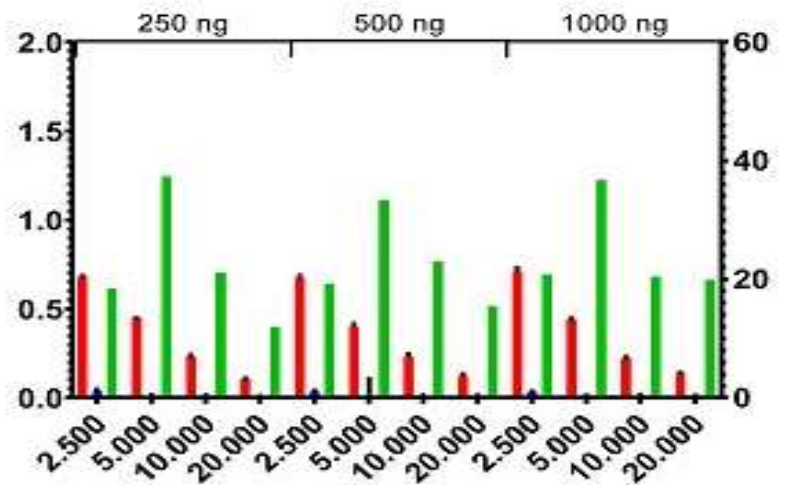

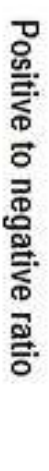

Figure 1. Comparison of antigen concentration (250,500, and $1000 \mathrm{ng})$, dilution ratio of serum $(1: 25$, 1:50, and 1:100 $\mathrm{v} / \mathrm{v})$ and secondary antibody $(1: 2,500-20,000 \mathrm{v} / \mathrm{v})$ by checkerboard analysis using iELISA test. Green and red bars indicate samples from positive and negative TB donors, respectively. (a) Antigen used: CFP10 protein; (b) Antigen used: ESAT6 protein.

\section{Interferon-Gamma Release Assay}

PBMCs from donors exposed to $M$. tuberculosis showed increased immunogenicity and high level of TNF-y when stimulated with different recombinant proteins concentrations (Figure 2). The cut-off of $145 \mathrm{pg}$ $\mathrm{mL}^{-1}$ of IFN- $\gamma$ was selected considering it provided the best differentiation between infected and non-infected patients. As displayed in Figure 2, the IFN-y production of the ATB group was significantly higher than that of the control group (healthy patients) after stimulation $(p<0.05)$. The IFN- $y$ levels were significantly higher in healthy individuals when stimulated with PPD in comparison with ESAT6, CFP10 and ESAT6:CFP10 stimulation $(p<0.0036)$. As expected, PPD did not distinguish between the exposure to BCG-vaccine and infections caused by other mycobacteria species, which resulted in some false positives cases. The CFP10:ESAT6 combination showed a tendency to promote higher reactivity in comparison to the antigens individually. 


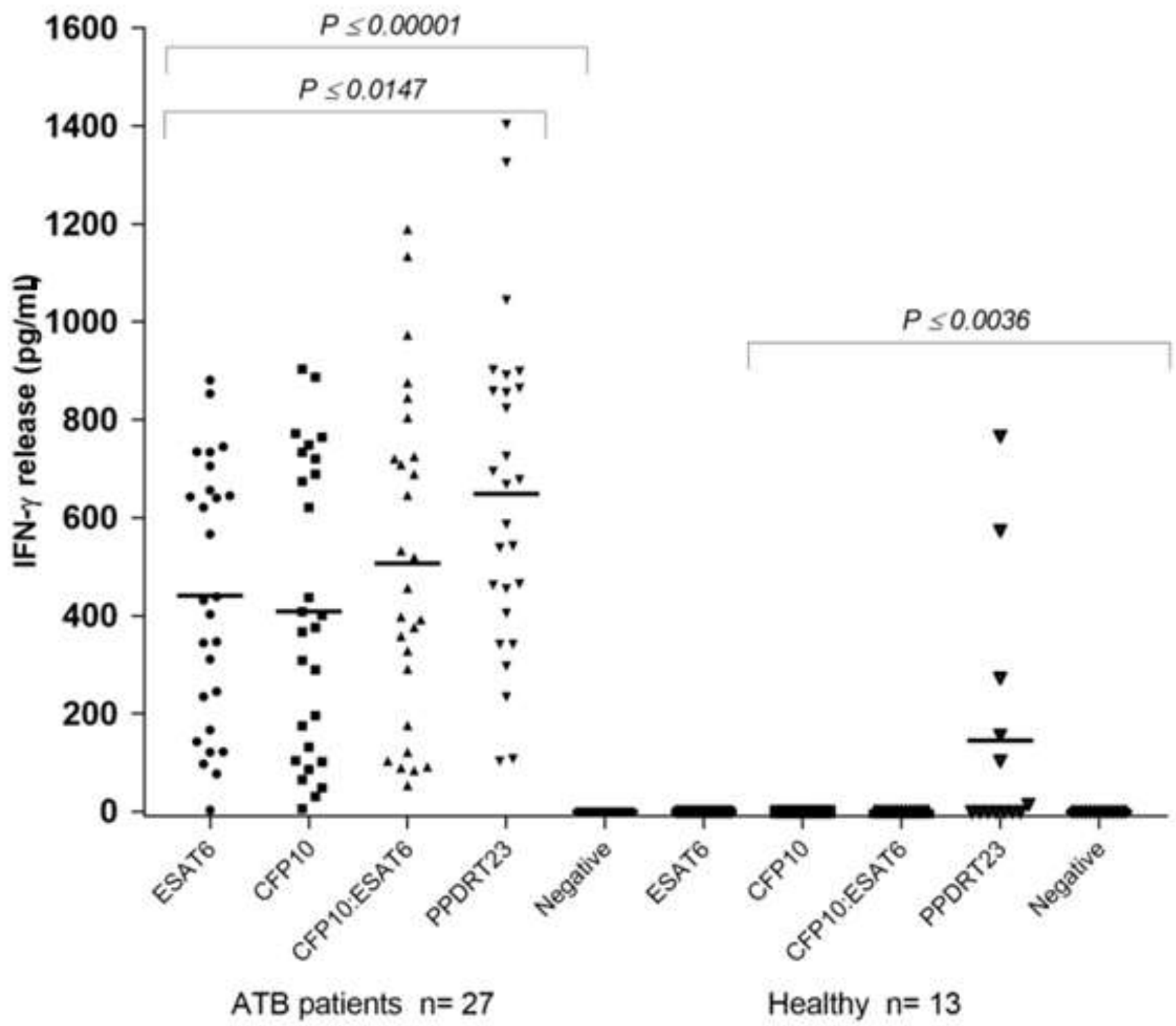

Figure 2. IFN-y release assay in the supernatant of PBMCs from two different groups of donors: active tuberculosis

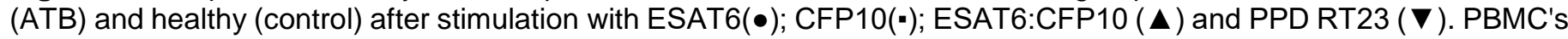
from 27 ATB patients and 13 healthy BCG-vaccinated donors were stimulated with $3 \mu \mathrm{g} \mathrm{mL}^{-1}$ of different antigens composition (ESAT6; CFP10; ESAT6:CFP10 and PPDRT23) after 5 days. For healthy donor samples, PPD RT23 was significantly different from negative control $(p<0.0036)$. For ATB donor samples, all formulations were different from negative control $(p<0.00001)$.

The number of positive responses by the IFN-y release test to the specific antigens and PPD among the 27 TB patients and the 13 healthy controls was used to evaluate sensitivity, specificity, positive (PPV) and negative predictive value (NPV), and likelihood ratio. They were presented to improve clinical interpretation with confidence intervals of 95\% (Table 1). The specificities for CFP10, ESAT6 and CFP10:ESAT6 were of $100 \%$, and sensitivities were of approximately 84,82 and $90 \%$, respectively. The specificity and sensitivity of PPD were 72 and $96 \%$, respectively. These results therefore suggest that combining the proteins CFP10 and ESAT6 was more efficient for diagnosing ATB than the current approach using PPD alone. 
Table 1. Sensibility, specificity, PPV, NPV, LR+ and LP- of different antigens (CFP10, ESAT6, CFP10:ESAT6 and PPD RT23) among PBMCs from ATB and healthy individuals by the IFN-y production in the diagnosis of tuberculosis.

\begin{tabular}{|c|c|c|c|c|}
\hline & \multicolumn{4}{|c|}{$\%$ (Confidence Intervals min - max) } \\
\hline & CFP10 & ESAT6 & CFP10:ESAT6 & PPD RT23 \\
\hline Sensitivity & $\begin{array}{c}84.38 \\
(67.21-94.72)\end{array}$ & $\begin{array}{c}81.82 \\
(64.54-93.02)\end{array}$ & $\begin{array}{c}90.00 \\
(73.47-97.89)\end{array}$ & $\begin{array}{c}96.43 \\
(81.65-99.91)\end{array}$ \\
\hline Specificity & $\begin{array}{c}100.00 \\
(75.29-100)\end{array}$ & $\begin{array}{c}100.00 \\
(75.29-100)\end{array}$ & $\begin{array}{c}100.00 \\
(75.29-100)\end{array}$ & $\begin{array}{c}72.22 \\
(46.52-90.31)\end{array}$ \\
\hline PPV & 100 & 100 & 100 & $\begin{array}{c}84.38 \\
(71.87-91.94)\end{array}$ \\
\hline NPV & $\begin{array}{c}72.22 \\
(53.75-85.33)\end{array}$ & $\begin{array}{c}68.42 \\
(51.24-81.71)\end{array}$ & $\begin{array}{c}81.25 \\
(59.70-92.69)\end{array}$ & $\begin{array}{c}92.86 \\
(65.00-98.91)\end{array}$ \\
\hline LR + & - & - & - & $\begin{array}{c}3.47 \\
(1.64-7.34)\end{array}$ \\
\hline LR - & $\begin{array}{c}0.16 \\
(0.07-0.35)\end{array}$ & $\begin{array}{c}0.18 \\
(0.09-0.37)\end{array}$ & $\begin{array}{c}0.10 \\
(0.03-0.29)\end{array}$ & $\begin{array}{c}0.05 \\
(0.01-0.35)\end{array}$ \\
\hline
\end{tabular}

Confidence interval of 95\%; PPV: positive predictive value; NPV: negative predictive value; LR +: likelihood ratio, positive result; LR -: likelihood ratio, negative result.

\section{Validation of the formulated product by delayed type hypersensitivity response in guinea pigs}

Individual delayed-type hypersensitivity (DTH) skin test responses to each sensitized group are shown in Figure 3. The results showed negative skin test in all non-sensitized animals, and no reaction was observed against the formulation components and the E. coli extract. In contrast, the recombinant proteins induced a DTH response in $M$. tuberculosis and $M$. bovis sensitized guinea pigs in both formulations evaluated $(>9.0$ $\mathrm{mm}$ ). All different protein concentrations tested induced a positive reaction level comparable to the positive control PPD RT23. The DTH response to CFP10 and ESAT6 was 9.0-14.0 mm and to the CFP10:ESAT6 combination was 11.0-16.0 mm in animals sensitized with $M$. tuberculosis. None of the purified recombinant proteins induced a positive response in $M$. avium and M. bovis BCG-sensitized guinea pigs. As predicted, the PPD did not distinguish the response between tuberculous and non-tuberculous mycobacteria. Accordingly, the positive DTH responses to PPD were detected in either M. tuberculosis, M. avium, M. bovis sensitized and BCG-vaccinated guinea pigs. A significantly enhanced response in $M$. tuberculosis sensitized animals was elicited by the formulation F2 containing the CFP10:ESAT6 combination at the concentration of $0.04 \mathrm{mg} \mathrm{mL}^{-1}$, in comparison to the standard PPD RT23 and the other formulations, as demonstrated by the ANOVA and the Tukey test $(p<0.01)$. 


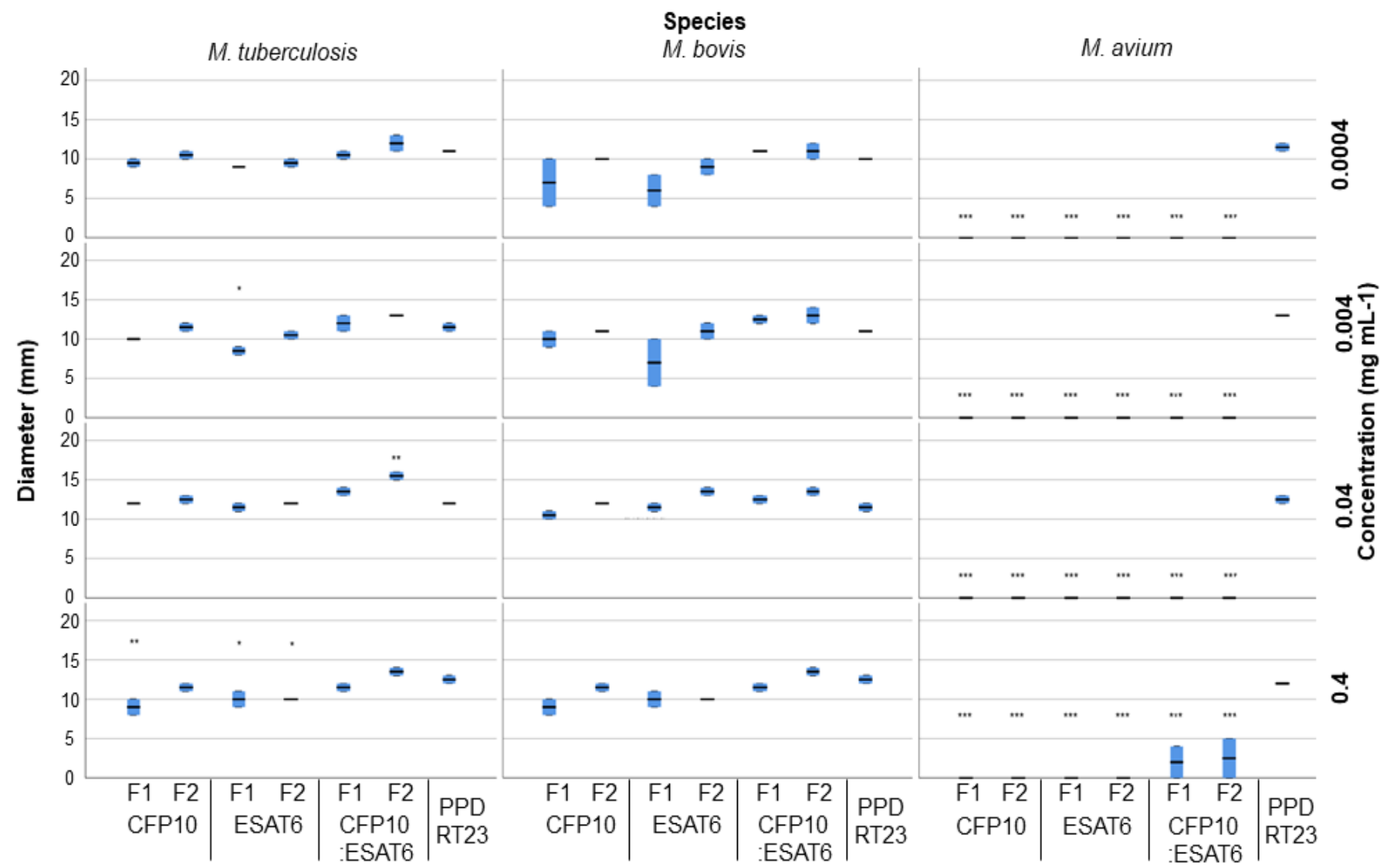

Figure 3. Analysis of skin test responses induced by different concentrations $\left(0.4,0.04,0.004\right.$, and $\left.0.004 \mathrm{mg} \mathrm{mL}^{-1}\right)$ of CFP10, ESAT6 and the combination of CFP10:ESAT6, in two different formulations (F1 and F2), in guinea pigs sensitized with $M$. tuberculosis, M. bovis and M. avium. The positive control was the commercial PPD RT23. The diameter of erythema was measured by double-blind method $48 \mathrm{~h}$ after injection. An induration of $\geq 5 \mathrm{~mm}$ was considered as a positive response. The significantly enhanced response in $M$. tuberculosis sensitized animals was elicited by the Formulation 2 containing the CFP10:ESAT6 combination at the concentration of $0.04 \mathrm{mg} \mathrm{mL}^{-1}$, in comparison to the standard PPD RT23 and the other formulations. $\left(^{*}\right)$ Significant difference by ANOVA and the Tukey test $(p<0.01)$.

\section{Stability of the formulated product}

Formulations $\mathrm{F} 1$ and $\mathrm{F} 2$ did not display variations regarding the stability parameters described previously. Also, the lyophilized form of the product remained stable in all conditions, while the soluble form showed variations in protein concentration, biological activity, and $\mathrm{pH}$ as functions of temperature variation.

All samples (liquid and lyophilized F1 and F2 stored at 5, 20, 40, -20 and $-80{ }^{\circ} \mathrm{C}$ ) exhibited normal aspect and color during the entire evaluation period ( $0-180$ days). Sterility was also verified in all samples during the whole period. Biological activity was confirmed in all samples except liquid F1 and F2 stored at $40{ }^{\circ} \mathrm{C}$ for $30,60,120$ and 180 days. Differences in $\mathrm{pH}$ and relative protein concentration were observed as a function of storage temperature for both formulations (Figure 4).

The $\mathrm{pH}$ ranged from 6.9 to 7.4 at various temperature conditions (Figure 4a). The values did not change more than $10 \%$, remaining compatible with the cutaneous $\mathrm{pH}$. Products intended for dermal administration should be isotonic and have a pH value close to neutral in aqueous vehicle [16].

One hundred percent stability of the recombinant protein was assured by freezing $\left(-20{ }^{\circ} \mathrm{C}\right.$ and $\left.-80{ }^{\circ} \mathrm{C}\right)$ during 180 days. Protein concentration at refrigeration temperature $\left(5^{\circ} \mathrm{C}\right)$ dropped by $26 \%$ and at room temperature by $77 \%$ over the evaluation period. The stability of the antigen formulations at elevated temperature $\left(40{ }^{\circ} \mathrm{C}\right)$ in the first 15 days decreased $56 \%$, followed by absence of biological activity and reduction of concentration after 30 days (Figure 4b).

After nine months of storage at room temperature, the lyophilized formulations maintained their aspect and color, with confirmed biological activity and $100 \%$ of relative protein concentration. 
(a)

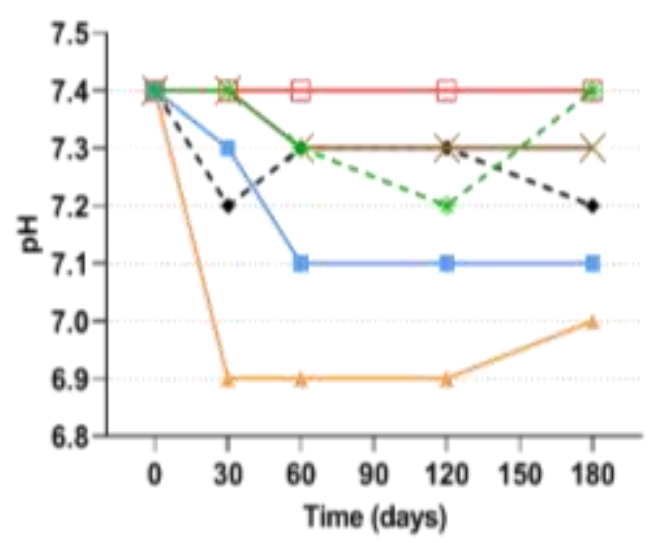

(b)

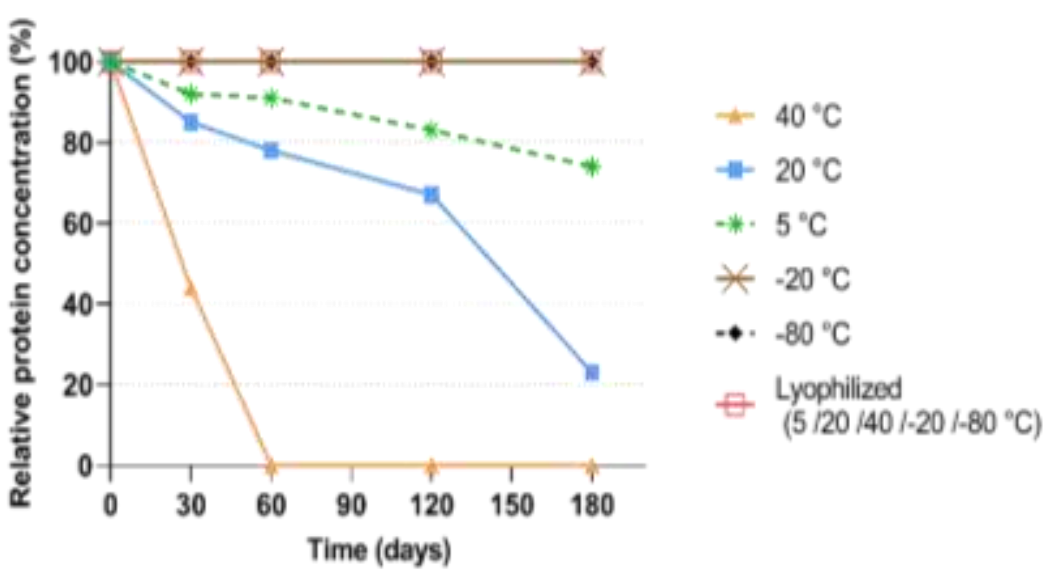

Figure 4. Stability of the formulated products represented by time-dependent variations of (a) $\mathrm{pH}$ and (b) relative protein concentration at different storage temperatures $\left(40,20,5,-20\right.$, and $\left.-80^{\circ} \mathrm{C}\right)$ in solution or lyophilized. Results are valid for formulations F1 and F2.

\section{DISCUSSION}

This study is the continuation of previous investigations of our research group that selected specific biomarkers to detect $M$. tuberculosis infection with high specificity and sensitivity. In the first step, seven recombinant secretory proteins of $M$. tuberculosis were produced using a cloning technology [14,15]. Since the large number of proteins can negatively affect the scale-up, quality, reproducibility and manufacturing cost, we selected two proteins (CFP10 and ESAT6) to continue the study and to evaluate different formulations for TB skin test and IFN-y production in PBMC. The selected proteins are considered the most promising candidates for a more accurate diagnosis in humans and animals [22-25]. Furthermore, these antigens are potential useful reagents for improved TB diagnosis based on DTH. Their high specificity is also an advantage, as they are not encoded in the genomes of any BCG vaccine strains or most species of NTM, except in M. marinum, M. kansasii, M. szulgai, M. flavescens and M. gastrii [26]. These antigens play multiple roles in $M$. tuberculosis virulence and are very prominent T-cell targets during the initial stages of TB infection $[14,15]$.

Our results showed that the DTH responses observed in sensitized animals are specific to $M$. tuberculosis and not due to formulation components, endotoxins or other $E$. coli protein contamination, thus proving quality, efficacy, and safety. To detect the best DTH response induced or elicited by the recombinant proteins, different concentrations were tested. The results at the concentration of $0.04 \mathrm{mg} \mathrm{mL}^{-1}$ of each recombinant protein demonstrated significantly higher rates of DTH than that obtained by using standard PPD. Furthermore, when combined, the recombinant proteins offered advanced diagnostic rate compared with single proteins and were shown as appropriate for specific diagnosis of $M$. tuberculosis and $M$. bovis infection. The development of formulation and the compatibility between active ingredients and excipients based on requirements of dosage, form and process are essential to ensure protein stability and prevent degradation. This study also analyzed the effect of the recombinant proteins prepared in two formulations (F1 and F2). The positive effect of F2 has been demonstrated at $0.04 \mathrm{mg} \mathrm{mL}^{-1}$, and this result revealed the importance of the right formulation not only for efficacy, but also for availability and compatibility of the final product. According to the animal-model studied here, the intradermal recombinant proteins test was safe and induced specific cellular immune responses. In addition, no adverse events or necrotic responses were reported. The safety of the recombinant CFP10-ESAT6 combination has already been demonstrated in clinical trials $[27,28]$.

The excipient selected for this experiment had two purposes: minimum reactogenicity and no adverse effects in animal models. The preparation that contains phenolic compound showed notable stability during an accelerated stress test. We assumed that the formulation could improve the antigen ability to stimulate the immune system by inducing the release of cytokines and also offer a promising alternative to stabilize and prolong the shelf-life. Accordingly [29], after phenol treatment, pro-inflammatory cytokine was selectively secreted, which acts as the main factor of macrophage mediation.

Physicochemical factors and operations including freeze-thaw cycles, formulation, and lyophilization can have important impacts on the product quality. It was observed that liquid formulations had to be stored 
frozen, at least at $-20^{\circ} \mathrm{C}$, in order to maintain their physicochemical characteristics. Storage at elevated temperature $\left(40^{\circ} \mathrm{C}\right)$ was especially harmful to their biological activity. Lyophilized formulations, however, could be stored at all temperatures without damage to physicochemical or biological properties during the evaluation period, and the shelf life at room temperature was of at least nine months. This is a very important feature to be considered for large scale application [30,31].

ESAT6 and CFP10 showed high sensitivity (90\%), and higher specificity (100\%) when compared to PPD (72\%), in patients diagnosed with TB, and low-level reactivity in BCG-vaccinated population reactive to PPD. The sensitivity of the recombinant proteins (90\%) was significantly lower than that of the PPD (96\%), and this could be attributed to a genetically diverse population with different growth stages and intracellular survival rates of the infectious agent. In fact, both antigens are very prominent T-cell targets in $M$. tuberculosisinfected humans, broadly recognized early during TB disease, and an ideal tool for diagnosis and infection control. In addition, these proteins have shown acceptable sensitivity and can potentially be used for recognition of latent tuberculosis in those who are at high risk for developing active disease at a later stage in life and in early cases of TB (preclinical).

\section{CONCLUSION}

In summary, our data suggest that the combination of these specific antigens, ESAT6 and CFP10, in the proposed formulations, can be a very useful supplementary tool for the diagnosis of active TB, in vitro and in vivo, to confirm or discard the first results, and a prominent tool to diagnose LTBI.

Funding: This research was supported by the funding agencies Coordenação de Aperfeiçoamento de Pessoal de Nível Superior - CAPES (AUX-PE-PNPD2847/2011 and Processo: 88881.505280/2020-01), Conselho Nacional de Desenvolvimento Científico e Tecnológico - CNPq (480292/2012-4), and Fundação Araucária (Project Pronex - 122).

Acknowledgments: Authors are thankful to Mr. Julio Salomão for all support given.

Conflicts of Interest: The authors declare no conflict of interest.

\section{REFERENCES}

1. Organization WH. Global TUBERCULOSIS Report 2020 - Executive summary. Geneva: World Health Organization. Geneva PP - Geneva: World Health Organization; 2020. 8 p.

2. Schluger NW. Improving the diagnosis of latent TB infection. Chest. 2017 Jun;151(6):1207-8.

3. de Miranda SS, de Almeida IN, Mansur M, de Assis Figueredo LJ, da Silva Carvalho W, Hadaad JPA, et al. Detection of drug resistant Mycobacterium tuberculosis strains using kit SIRE nitratase $\AA$ : A multicenter study. Brazilian Arch Biol Technol. 2020.

4. Bai X, Liang $\mathrm{Y}$, Yang $\mathrm{Y}$, Zhang J, Wu X. A new method of screening for latent tuberculosis infection: results from army recruits in Beijing in 2014. Immunol Lett. 2017 Jun;186:28-32.

5. Benabdesselem C, Barbouche MR, Jarboui MA, Dellagi K, Ho JL, Fathallah DM. High level expression of recombinant Mycobacterium tuberculosis culture filtrate protein CFP32 in Pichia pastoris. Mol Biotechnol. 2007;35(1):41-9.

6. Aghababa H, Mohabati Mobarez A, Khoramabadi N, Behmanesh M, Mahdavi M, Tebianian M, et al. A comparative approach to strategies for cloning, expression, and purification of M. tuberculosis mycolyl transferase 85B and evaluation of immune responses in BALB/c Mice. Mol Biotechnol. 2014;56(6):487-97.

7. Hemmati M, Seghatoleslam A, Rasti M, Ebadat S, Mosavari N, Habibagahi M, et al. Expression and purification of recombinant Mycobacterium tuberculosis (TB) Antigens, ESAT-6, CFP-10 and ESAT- 6/CFP-10 and their diagnosis potential for detection of TB patients. Iran Red Crescent Med J. 2011/08/01. 2011 Aug;13(8):556-63.

8. Renshaw PS, Lightbody KL, Veverka V, Muskett FW, Kelly G, Frenkiel TA, et al. Structure and function of the complex formed by the tuberculosis virulence factors CFP-10 and ESAT-6. EMBO J. 2005 Jul;24(14):2491-8.

9. Li F, Xu M, Zhou L, Xiong Y, Xia L, Fan X, et al. Safety of recombinant fusion protein ESAT6-CFP10 as a skin test reagent for tuberculosis diagnosis: an open-label, randomized, single-center phase i clinical trial. Rosenberg $\mathrm{HF}$, editor. Clin Vaccine Immunol. 2016 Sep;23(9):767-73.

10. Li F, Xu M, Qin C, Xia L, Xiong Y, Xi X, et al. Recombinant fusion ESAT6-CFP10 immunogen as a skin test reagent for tuberculosis diagnosis: an open-label, randomized, two-centre phase 2a clinical trial. Clin Microbiol Infect. 2016 Oct;22(10):889.e9-889.e16.

11. Wang W, Singh S, Zeng DL, King K, Nema S. Antibody structure, instability, and formulation. J Pharm Sci. 2007 Jan;96(1):1-26.

12. Sharma SK, Vashishtha R, Chauhan LS, Sreenivas V, Seth D. Comparison of TST and IGRA in diagnosis of latent tuberculosis infection in a High TB-Burden setting. Hasnain SE, editor. PLoS One. 2017 Jan;12(1):e0169539.

13. Li G, Li F, Zhao H-M, Wen H-L, Li H-C, Li C-L, et al. Evaluation of a New IFN-y Release assay for rapid diagnosis Brazilian Archives of Biology and Technology. Vol.64: e21210127, 2021 www.scielo.br/babt 
of active tuberculosis in a high-incidence setting. Front Cell Infect Microbiol. 2017 Apr;7.

14. DelaColetta Troiano Araújo L, Wibrantz M, Rodríguez-Fernández DE, Karp SG, Talevi AC, Souza EM, et al. Process parameters optimization to produce the recombinant protein CFP10 for the diagnosis of tuberculosis. Protein Expr Purif. 2019 Feb;154:118-25.

15. Malaghini M, Thomaz-Soccol V, Probst CM, Krieger MA, Preti H, Kritski A, et al. Recombinant antigen production for assays of intradermoreaction for diagnosis and surveillance of tuberculosis. J Biotechnol. 2011 Oct;156(1):568.

16. Liu S, Tobias R, McClure S, Styba G, Shi Q, Jackowski G. Removal of endotoxin from recombinant protein preparations. Clin Biochem. 1997 Aug;30(6):455-63.

17. Hendriksen CFM. Introduction: laboratory animals and immunization procedures: challenges and opportunities. ILAR J. 2005;46(3):227-9.

18. Sengupta $\mathrm{P}$, Chatterjee $\mathrm{B}$, Tekade RK. Current regulatory requirements and practical approaches for stability analysis of pharmaceutical products: A comprehensive review. Int J Pharm. 2018 May;543(1-2):328-44.

19. Bradford MM. A rapid and sensitive method for the quantitation of microgram quantities of protein utilizing the principle of protein-dye binding. Anal Biochem. 1976 May;72:248-54.

20. Parveen S, Kaur S, David SAW, Kenney JL, McCormick WM, Gupta RK. Evaluation of growth based rapid microbiological methods for sterility testing of vaccines and other biological products. Vaccine. 2011 Oct;29(45):8012-23.

21. ICH. Harmonized tripartite guideline: photostability testing of new drug substances and products, ICH-Q113, Nov. 1996. Fed Regist. 1996;62:27115-22.

22. Mahmoudi S, Mamishi S, Ghazi M, Hosseinpour Sadeghi R, Pourakbari B. Cloning, expression and purification of Mycobacterium tuberculosis ESAT-6 and CFP-10 antigens. Iran J Microbiol. 2013 Dec;5(4):374-8.

23. Pai M, Denkinger CM, Kik S V., Rangaka MX, Zwerling A, Oxlade O, et al. Gamma interferon release assays for detection of Mycobacterium tuberculosis infection. Clin Microbiol Rev. 2014 Jan;27(1):3-20.

24. Scarpellini P, Tasca S, Galli L, Beretta A, Lazzarin A, Fortis C. Selected pool of peptides from ESAT-6 and CFP10 proteins for detection of Mycobacterium tuberculosis infection. J Clin Microbiol. 2004 Aug;42(8):3469-74.

25. Wu X, Li Q, Liang Y, Yang Y, Zhang J, Liang J, et al. Clinical evaluation of a homemade enzyme-linked immunospot assay for the diagnosis of active tuberculosis in China. Mol Biotechnol. 2011 Jan;47(1):18-25.

26. Van Ingen J, de Zwaan R, Dekhuijzen R, Boeree M, van Soolingen D. Region of difference 1 in nontuberculous Mycobacterium species adds a phylogenetic and taxonomical character. J Bacteriol. 2009 Sep;191(18):5865-7.

27. Bergstedt W, Tingskov PN, Thierry-Carstensen B, Hoff ST, Aggerbeck H, Thomsen VO, et al. First-in-Man Open Clinical trial of a combined rdESAT-6 and rCFP-10 tuberculosis specific skin test reagent. Dheda K, editor. PLoS One. 2010 Jun;5(6):e11277.

28. Aggerbeck H, Giemza R, Joshi P, Tingskov PN, Hoff ST, Boyle J, et al. Randomised clinical trial investigating the specificity of a novel skin test (c-tb) for diagnosis of M. tuberculosis infection. Goletti D, editor. PLoS One. 2013 May;8(5):e64215.

29. Weber C, Kammerer D, Streit B, Licht AH. Phenolic excipients of insulin formulations induce cell death, proinflammatory signaling and MCP-1 release. Toxicol Reports. 2015;2:194-202.

30. Wang W. Advanced protein formulations. Protein Science. 2015.

31. Manzoor Z, Nawaz A, Mukhtar H, Haq I. Bromelain: methods of extraction, purification and therapeutic applications. Brazilian Arch Biol Technol. 2016.

2021 by the authors. Submitted for possible open access publication under the terms and conditions of the Creative Commons Attribution (CC BY NC) license (https://creativecommons.org/licenses/by-nc/4.0/). 